\title{
MAILLARD REACTION PRODUCTS AS MARKERS OF THE DURUM WHEAT PASTA MANUFACTURING PROCESS: A COMMODITY INVESTIGATION
}

\author{
E. Testani ${ }^{\mathrm{a}}$, V. Giannetti ${ }^{\mathrm{b} *}, \mathrm{M}$. Boccacci Mariani $^{\mathrm{b}}$ and P. Mannino ${ }^{\mathrm{b}}$ \\ ${ }^{a}$ Consiglio per la ricerca in agricoltura e l'analisi dell'economia agraria, Centro per lo studio delle relazione tra \\ pianta e suolo (CREA-RPS), Via della Navicella 2, 00184 Rome. Italy \\ ${ }^{b}$ Department of Management, Faculty of Economy, Sapienza University of Rome, Via del Castro Laurenziano 9, \\ 00161 Rome. Italy
}

(Received: 29 May 2015; accepted: 6 August 2015)

\begin{abstract}
In the present work, three volatile Maillard reaction products (maltol, furfuryl alcohol, and furfural) were considered for their supposed ability to act as process markers of dry durum wheat pasta. Hence, a commodity investigation was performed on Made in Italy pasta products and the HS-SPME/GC-MS technique was adopted to detect the target compounds in sixty samples. The analysis of variance (ANOVA) was used to evaluate whether the relative abundance of the flavour compounds can differentiate pasta samples processed through mild technologies (traditional methods) from that submitted to intense thermal stress during their elaboration (industrial methods). Results showed that the analysed products were efficiently discriminated according to their claimed manufacturing method by maltol, furfuryl alcohol, and furfural, which thus can serve as reliable pasta process indicators.
\end{abstract}

Keywords: flavour, HS-SPME, Maillard reaction products, pasta

Besides texture, colour, nutritional and cooking properties (ACQUistucCI, 2000; PAGNOTTA et al., 2005), many other features affecting the quality of durum wheat pasta should be taken into consideration to properly characterize different products. In particular, pasta flavour has not been deeply investigated yet (BeLEGGiA et al., 2009; West et al., 2013), although this sensory property has a relevant influence on consumer acceptability. Since flavour composition of thermally-processed foodstuffs is generally affected by the conditions (temperature, air moisture, duration) adopted during their processing (SUCAN \& WEERASINGHE, 2005), the analysis of volatiles profile may allow the identification of new process markers able to discriminate the large selection of Made in Italy pasta products available on the market depending on their different manufacturing conditions. In fact, high temperature-dried pasta shows higher levels of furan and furan derivatives, derived from the Maillard reaction, than low temperature-dried pasta (PASQUALONE et al., 2014).

In Italy, traditional pasta production involve the adoption of mild technologies relying on low temperature (around $50^{\circ} \mathrm{C}$ ) and long time (around $24 \mathrm{~h}$ ) drying methods (LT-Lt), which results in products with peculiar organoleptic properties. The industrial production, instead, relies on plants that operate continuously and require the use of a drying step performed at high $\left(60-80{ }^{\circ} \mathrm{C}\right)$ or very high $\left(80-100{ }^{\circ} \mathrm{C}\right)$ temperatures within a short time (5-12 $\mathrm{h}$ for HT-St or $1-2 \mathrm{~h}$ for VHT-St) (DEXTER \& MARChYLO, 2001). As a result of the lower operation and maintenance costs associated with large-scale production, pasta produced by traditional methods is on average more expensive $\left(\geq 4 € \mathrm{~kg}^{-1}\right)$ than industrially produced one $\left(\leq 2 € \mathrm{~kg}^{-1}\right)$. Beside a significant reduction in overall cost, the adoption of HT-St or VHT-St

\footnotetext{
* To whom correspondence should be addressed.

Phone: +39-0649766522; e-mail: vanessa.giannetti@uniroma1.it
} 
methods bring some advantages in terms of plant productivity, reduction of microbial contamination, as well as improvements in pasta digestibility (partial denaturation of proteins), and texture during cooking (PAVAN, 1980).

On the other hand, when the drying step takes place above $60{ }^{\circ} \mathrm{C}$, pasta nutritional value and flavour undergo remarkable changes due to the development of uncontrolled crossreactions such as the Maillard reaction (RESMINI et al., 1993, ANESE et al., 1999). The chemistry involved in the Maillard reaction is extremely complex and partially still unknown (AMES, 1998). Since several Maillard reaction products (MRPs) have a direct impact on the nutritional and sensory quality of foodstuffs (VAN BoEKel, 2006; GiannetTI et al., 2013), some volatile compounds formed during pasta drying (e.g. aromatic aldehydes and alcohol, ketons, furanderivatives, pyrazines, thiophenes (PASQUALONE et al., 2014)) could significantly affect pasta flavour due to their low odour threshold values (LEONARDos et al., 1969).

The present study was based on the hypothesis that the MRPs, characterizing the flavour of durum wheat pasta, should be detected at higher amounts in products dried with HT-St or VHT-St methods, as the Maillard reaction progression is prompted by drastic thermal treatments. Therefore, a significant variation in the relative amount of volatile MRPs should allow the discrimination between traditionally produced pasta samples and industrial ones. Among the different volatile products of the Maillard reaction, furfural, generally considered as a good indicator of food thermal damage, was selected as possible marker of pasta flavour. In addition, as previous studies (Folkes \& Gramshaw, 1977; BeAl \& MotTram, 1994) have shown the presence of maltol and furfuryl alcohol in the flavour of bread crust and other cereal-based processed foods, also these MRPs were investigated as potential markers of pasta manufacturing process.

In this study, the Headspace-Solid Phase Micro-Extraction (HS-SPME) technique coupled with Gas Chromatography-Mass Spectrometry (GC-MS) was employed to investigate the presence of the target MRPs in the flavour of 60 dry pasta products (30 industrial samples and 30 marketed as traditional ones). Data were evaluated through relative quantitative analysis followed by analysis of variance (ANOVA) for statistical significance.

The work focused on a commodity investigation among pasta products of the Italian market - many of which are widely exported worldwide and belong to the main pasta brands - in order to assess the applicability of the target compounds as reliable process/quality markers.

\section{Materials and methods}

\subsection{Samples}

Samples belonging to the two main market categories were analysed. Industrial pasta samples, both private labels and large firms, were purchased from large-scale retail trade channels, while pasta samples claimed as "produced according to traditional methods" (slow drying at low temperature) were obtained from specialized shops (i.e. Pasta of Gragnano P.G.I., handicraft products). Samples were also classified by considering the average selling price ( $\leq 3 € \mathrm{~kg}^{-1}$ for mass-produced pasta products and $\geq 5 € \mathrm{~kg}^{-1}$ for traditional ones). Further differentiation among samples within the two categories was taken into account, selecting both short-shaped pasta samples (such as rigatoni, penne, etc.) and long-shaped pasta ones (such as spaghetti, linguine, etc.). Overall 60 pasta samples differing in brand, shape, and drying method were collected. Packaged samples were kept at room temperature until being analysed. 

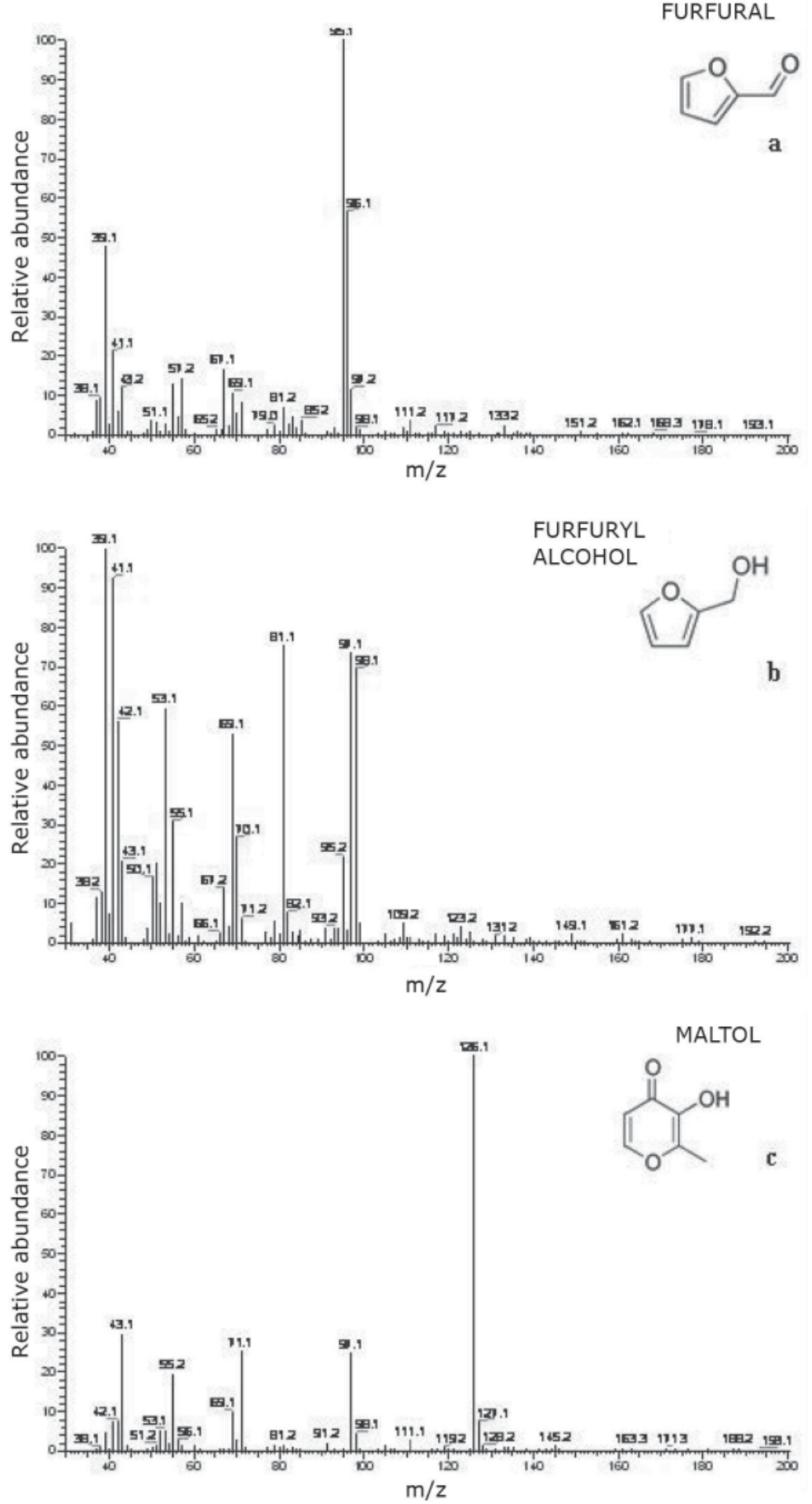

Fig. 1. Mass spectra of the volatiles of Maillard reaction selected as standards 


\subsection{Determination of the flavoured compounds}

In order to identify volatile compounds in pasta samples, the static headspace solid-phase micro-extraction (HS-SPME) technique was adopted. 3-Hydroxy-2-methyl-4-pyrone (maltol), 2-furanmethanol (furfuryl alcohol), and furan-2-carbaldehyde (furfural), all $\geq 99 \%$ purity, were purchased from Sigma-Aldrich (St. Louis, MO, USA). Deuterated tetrahydrofuran (d8-THF) supplied by Sigma-Aldrich (St. Louis, MO, USA) was used as the internal standard (IS) added at $0.01 \mu \mathrm{g}^{-1}$ to the samples. Standard solutions were prepared with deionised water, obtained by a Milli-Q water purification System (Millipore, Bedford, MA, USA) and stored in the dark at $4{ }^{\circ} \mathrm{C}$. The volatile compounds were identified in the flavour of pasta samples by comparing their mass spectra with those of the corresponding standard solutions (Fig. 1).

Standard mass spectra were acquired by HS-SPME extraction of $1 \mu 1$ of mix standard solutions at $600 \mu \mathrm{g} \mathrm{l}^{-1}$ in a $20 \mathrm{ml}$ glass vial. Afterward, the mass spectra were used to build up a compound library by the Automated Mass Spectral Deconvolution and Identification System 258 (AMDIS) software, and then used for the acquisition of the compound peak area and the screening of pasta samples.

The sample preparation, the HS-SPME and GC-MS equipments, and methods are described elsewhere (BOCCACCI MARIANI et al., 2014). Analyses were performed in triplicate for each sample.

\subsection{Statistics and software}

Statistical analysis for data significance was performed using the SPSS 16.0 package (IBM SPSS Statistics, Chicago, IL, USA). One-way univariate analysis of variance (ANOVA) was carried out for each target compounds detected in pasta flavour by using the manufacturing process (traditional or industrial) as the main factor. Subsequently, the assumption that also shape could influence the relative abundance of the investigated MRPs was taken into consideration, since short-shaped and long-shaped samples have very different specific surface area available for water evaporation during the drying step. Hence, a second factor at two levels was included in ANOVA analysis for each compound. The final data set included results of the analysis of differently-shaped pasta samples (long-shaped and short-shaped) produced by traditional or industrial methods. Mean comparison was carried out according to the Least Square Difference (LSD) test and for variables with significant factors interaction, the Duncan Multiple Range Test (DMRT), both at $\mathrm{P} \leq 0.05$ probability level.

\section{Results and discussion}

\subsection{Identification of the target Maillard reaction products in pasta flavour}

The HS-SPME/GC-MS profile of durum wheat pasta flavour is characterized by a wide selection of volatile compounds (BeLEGGia et al., 2011; BocCACCI Mariani et al., 2014; PASQUALONE et al., 2014), some of which are attributable to the development of the Maillard reaction during pasta drying (Yaylayan \& Mandeville, 1994; Pozo-Bayón et al., 2006; Barham et al., 2010; Smuda \& Glomb, 2013). The investigated MRPs were identified in the flavour profile of all samples (retention times: furfural $15.36 \mathrm{~min}$; furfuryl alcohol $19.66 \mathrm{~min}$; maltol $24.00 \mathrm{~min}$ ) (Fig. 2). 


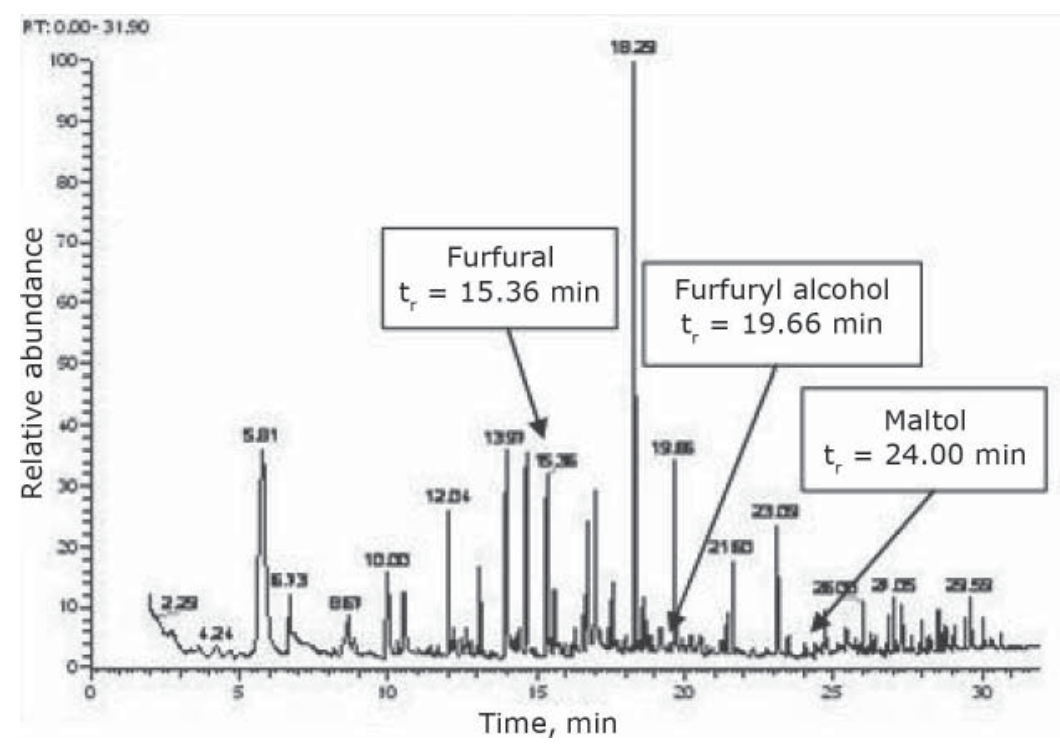

Fig. 2. HS-SPME/GC-MS chromatographic profile of a pasta sample

\subsection{Method precision and relative quantitative analysis}

In the analysis of food flavour, the ideal extraction conditions for HS-SPME are not readily achieved, since volatile compounds are continually formed and degraded through a complex pattern of chemical reactions depending on temperature, moisture, and pressure (BREDIE et al., 2002; Grimm et al., 2002). Most of the literature on SPME technique applied to foodstuffs is related to qualitative analysis, however, quantitative information can be obtained by analysing the samples under constant conditions and measuring the relative production/ release of the volatile compounds in the headspace (KАтАокA et al., 2000). For solid food samples, the matrix spiking procedure generally does not provide reliable results, since the mass-transfer mechanism can be very different for spiked analytes compared to native ones (OUYANG \& PAWLISZYN, 2008). Nevertheless, the headspace analysis performed by the internal standard method yields a gas chromatographic profile that can be used to evaluate the relationship between the relative concentration of flavoured compounds and the overall sensory quality of food. By this approach, the HS-SPME procedure could be suitable for the comparison of pasta samples produced by different manufacturing processes.

In this study, relative quantification of the three MRPs was performed using the internal standard (deuterated THF) method and normalized data were then processed in order to assess statistically significant differences among the considered pasta categories. To the purpose, a preliminary evaluation of the method precision was carried out. The repeatability and intermediate precision, expressed as a percentage relative standard deviation (RSD\%), were calculated on ratio of analyte and internal standard areas $\left(\mathrm{A} / \mathrm{A}_{\mathrm{IS}}\right)$ expressed as total ion counts (TIC) by analysing a pasta sample three times during the same day and processing the same sample three times each day for five subsequent days. Good results were achieved for 
all the target compounds, since repeatability was $0.2,1.4,4.3 \%$ and intermediate precision $1.0,2.6,5.8 \%$ for maltol, furfural, and furfuryl alcohol, respectively.

\subsection{Statistical analysis}

ANOVA results on relative quantification for maltol, furfural, and furfuryl alcohol detected in the analysed pasta samples are reported in Table 1. As expected, factors significantly influenced the measured parameters. Moreover, the interaction between the factors indicated that the effect on the content of maltol and furfuryl alcohol varied according to the different combination of process and shape. Two-way ANOVA analysis among the four sub-groups was therefore carried out for the two compounds. Results highlighted that maltol was significantly able to differentiate all the analysed groups of samples with the highest values in long-shaped industrial samples and the lowest ones in short-shaped traditional pasta, as expected. Differently, even though the relative amount of furfuryl alcohol was significantly higher in traditional pasta groups than in the industrial ones, no significant differences were observed between the long-shaped and short-shaped traditional samples (data not shown). The results clearly showed that all the investigated compounds were able to discriminate the samples in respect to the process factor with significantly higher response in industrial samples than in traditional ones. Moreover, the results confirmed the effect of shape factor on the MRPs content (CAVAzZA et al., 2013). Indeed, during the drying step, long-shaped pasta has higher specific surface area exposed to heat exchange and water loss than short-shaped one, causing higher internal temperature and water activity gradients (LiтchField \& Окоs, 1992), which could enhance the formation kinetics of MRPs. As a result, the formation of the MRPs is expected to be favoured in long-shaped pasta as well confirmed by this product investigation.

Table 1. ANOVA results of Maillard reaction products in the analysed pasta samples along the process and shape factor

\begin{tabular}{lccc}
\hline Factor & Maltol & Furfural & Furfuryl alcohol \\
\hline Process & $* * *$ & $* *$ & $* * *$ \\
Shape & $* * *$ & $* *$ & $* * *$ \\
Process $\times$ Shape & $* *$ & n.s. & $*$ \\
\hline
\end{tabular}

n.s.: not significant; *: $\mathrm{P} \leq 0.05 ; * *: \mathrm{P} \leq 0.01 ; * * *$ : $\mathrm{P} \leq 0.001$

\section{Conclusions}

The study results clearly showed the discrimination of the pasta products by the three markers according to the manufacturing method and the further effect of shape on the MRPs formation. This finding represents an interesting novelty, since to date, maltol and furfuryl alcohol have never been used as food process/quality markers, in contrast to furfural, which is considered as a reliable indicator of product deterioration (e.g. honey, spirits, fruit juices) (NAGY \& RANDALl, 1973; JeuRING \& KupPeRs, 1980) and an index of thermal process conditions (e.g. oils, milk, infant formula) (Ferrer et al., 2000; Durmaz \& GöKMEN, 2010). The results obtained in this work encourage further investigations in order to assess whether these MRPs 
could also serve as innovative markers for detecting heat alteration and flavour deterioration in other categories of processed foodstuffs, including those generally not considered for their flavour properties like Italian dry pasta.

\section{References}

Acquistucci, R. (2000): Influence of Maillard reaction on protein modification and colour development in pasta. Comparison of different drying conditions. LWT-Food Sci. Technol., 33, 48-52.

Ames, J.M. (1998): Applications of the Maillard reaction in the food industry. Food Chem., 62, 431-439.

Anese, M., Nicoli, M.C., Massini, R. \& Lerici, C.R. (1999): Effects of drying processing on the Maillard reaction in pasta. Food Res. Int., 32, 93-199.

Barham, P, Skibsted, L.H., Bredie, W.L., Bom Frøst, M., Møller, P.J., Snitkjaer, P. \& Mortensen, L.M. (2010): Molecular gastronomy: a new emerging scientific discipline. Chem. Rev., 110, 2313-2365.

Beal, A.D. \& Mottram, D.S. (1994): Compounds contributing to the characteristic aroma of malted barley. J. Agr. Food Chem., 42, 2880-2884.

Beleggia, R., Platani, C., Spano, G., Monteleone, M. \& Cattivelli, L. (2009): Metabolic profiling and analysis of volatile composition of durum wheat semolina and pasta. J. Cereal Sci., 49, 301-309.

Beleggia, R., Platani, C., Papa, R., Di Chio, A., Barros, E., Mashaba, C., Wirth, J., Fammartino, A., Sautter, C., Conner, S., Rauscher, J., Stewart, D. \& Cattivelli, L. (2011): Metabolomics and food processing: From semolina to pasta. J. Agr. Food Chem., 59, 9366-9377.

Boccacci Mariani, M., Giannetti, V. \& Testani, E. (2014): HS-SPME/GC-MS method to characterise the flavor of Italian pasta: potential application to assess the quality of the products. Food Anal. Method., 7, 64-72.

Bredie, W.LP., Mottram, D.S. \& Guy. R.C.E. (2002): Effect of temperature and pH on the generation of flavor volatiles in extrusion cooking of wheat flour. J. Agr. Food Chem., 50, 1118-1125.

Cavazza, A., Corradini, C., Rinaldi, M., Salvadeo, P., Borromei, C. \& Massini, R. (2013): Evaluation of pasta thermal treatment by determination of carbohydrates, furosine, and color indices. Food Bioprocess. Tech., 6 , $2721-2731$

Dexter, J.E. \& Marchylo, B.A. (2001): Recent trends in durum wheat milling and pasta processing: Impact on durum wheat quality requirements. Colloques-INRA, 99, 139-164.

Durmaz, G. \& GöKmen, V. (2010): Determination of 5-hydroxymethyl-2-furfural and 2-furfural in oils as indicators of heat pre-treatment. Food Chem. 123, 912-916.

Ferrer, E., Alegria, A., Courtois, G. \& Farre, R. (2000): High-performance liquid chromatographic determination of Maillard compounds in store-brand and name-brand ultra-high-temperature-treated cows' milk. J. Chromatogr. A, 881, 599-606.

Folkes, D.J. \& Gramshaw, J.W. (1977): Volatile constituents of white bread crust. Int. J. Food Sci. Tech., 12, 1-8.

Giannetti, V., Boccacci Mariani, M. \& Mannino, P. (2013): Furosine as a pasta quality marker: evaluation by an innovative and fast chromatographic approach. J. Food Sci., 78, 994-999.

Grimm, C.C., Champagne, E.T. \& Oktsuba, K. (2002): Analysis of volatile compounds in the headspace of rice using SPME/GC/MS. -in: MARsili, R. (Ed.) Flavor, fragrance, and odor analysis, Marcel Dekker; New York, NY, USA, pp. 229-248.

Jeuring, H.J. \& Kuppers, F.J.E.M. (1980): High performance liquid chromatography of furfural and hydroxymethylfurfural in spirits and honey. J. AOAC, 63, 1215-1218.

Kataoka, H., Lord, H.L. \& Pawliszyn, J. (2000): Applications of solid-phase microextraction in food analysis. J. Chromatogr. A, 880, 35-62.

Leonardos, G., Kendall, D. \& Barnard, N. (1969): Odour threshold determinations of 53 odorant chemicals. J. Air Pollut. Control Assoc., 19, 91-95.

Litchfield, B.J. \& Okos, M.R. (1992): Moisture diffusivity in pasta during drying. J. Food Eng., 17, $117-142$.

NAGY, S. \& RANDALL, V. (1973): Use of furfural content as an index of storage temperature abuse in commercially processed orange juice. J. Agr. Food Chem., 21, 272-275.

Ouyang, G. \& Pawliszyn, J. (2008): A critical review in calibration methods for solid-phase microextraction. Anal. Chim. Acta, 627, 184-197.

Pagnotta, M.A., Blanco, A., Gadaleta, A. \& Fares, C. (2005): Functional determinants of grain quality. -in: Royo, C., Nachit, M.M., Di Fonzo, N., Araus, J.L., Pfeiffer, W.H. \& Slaferm, G.A. (Eds) Durum wheat breeding. Current approaches and future strategies, Food Products Press, Binghamton, NY, USA, pp. 483-527. 
Pasqualone, A., Paradiso, V.M., Summo, C., Caponio, F. \& Gomes, T. (2014): Influence of drying conditions on volatile compounds of pasta. Food Bioprocess. Tech., 7, 719-731.

Pavan, G. (1980): High temperature drying improves pasta quality. Food Eng. Int., 5, 37-39.

Pozo-Bayón, M.A., Guichard, E. \& CAYOT, N. (2006): Flavor control in baked cereal products. Food Rev. Int., 22, 335-379.

Resmini, P., Pellegrino, L., Pagani, M.A. \& De Noni, I. (1993): Formation of 2-acetyl-3-D-glucopyranosylfuran (glucosylisomaltol) from nonenzymatic browning in pasta drying. Italian J. Food Sci., 5, 341-353.

Smuda, M. \& Glomb, M.A. (2013): Fragmentation pathways during Maillard-induced carbohydrate degradation. $J$. Agr. Food Chem., 61, 10198-10208.

Sucan, M. \& Weerasinghe, D. (2005): Process and reaction flavors: an overview. -in: Weerasinghe, D. \& Sucan, M. (Eds) Process and reaction flavors. Recent developments, American Chemical Society, Washington DC, USA, pp. 1-23.

VAN BOEKel, M.A.J.S. (2006): Formation of flavor compounds in the Maillard reaction. Biotechnol. Adv., 24, 230233.

Yaylayan, V.A. \& MandeVilLe, S. (1994): Stereochemical control of maltol formation in Maillard reaction. J. Agr. Food Chem., 42, 771-775.

West, R., Seetharaman, K. \& Duizer, L.M. (2013): Effect of drying profile and whole grain content on flavor and texture of pasta. J. Cereal Sci., 58, 82-88. 